\title{
UNA VISIÓN HISTÓRICA A LA OBRA DE RAFAEL ARANGO VILLEGAS
}

$(1889-1952)^{*}$

\author{
Oscar Manuel Agudelo Ramírez (In memorian) ${ }^{\star \star}$
}

\author{
Después de tantas y de tan pequeñas \\ cosas, -busca el espíritu mejores aires, \\ mejores aires \\ (...) \\ Y yo -Gaspar- me voy con el morral de mis caprichos, \\ todo derecho, lógicamente, hacia el absurdo, \\ dejando de lado, dejando de lado ruidos inanes \\ de ventolina. \\ León de Greiff. El Relato de Gaspar En: "Prosas de Gaspar” (1937)
}

Resumen: Este ensayo se preguntará por la posibilidad de usar algunas obras del manizalita Rafael Arango Villegas como herramientas para hacer Historia, así como por las características narrativas que permiten otorgarle dicha connotación.

Palabras clave: narrativa, Manizales, tradición, cultura, representaciones, relación dialéctica.

\footnotetext{
* Disertación basada en la ponencia presentada el día 29 de abril de 2015 en el marco del III Congreso Colombiano de Estudiantes de Historia, Universidad de Caldas (Manizales, Colombia) Mesa Temática 4: Intelectuales y Prensa

** Oscar Manuel Agudelo Ramírez (Enero 22 de 1983 - Mayo 16 de 2015) Estudiante de Licenciatura en Historia. Universidad del Valle, sede Cali. Esta ponencia hacia parte del proyecto de investigación monográfica, truncado por su fallecimiento, titulado "La tragedia de la modernidad en Rafael Arango Villegas. "Asistencia y Camas"... y otros relatos". Dirigido por Judith C. González Erazo. E-Mail: oscartostao@live.com.ar. ... "a tu memoria literaria viejo Gaspar".
} 


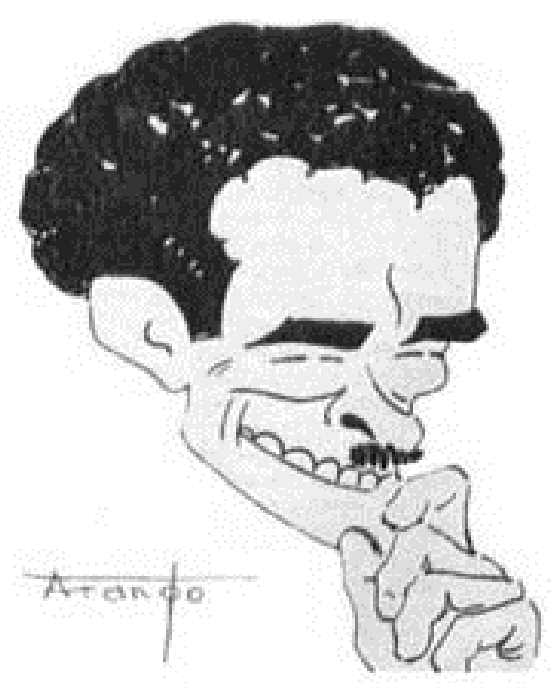

Fuente: Portada "Obras Completas", Rafael Arango Villegas. (1955) Prólogo de Eduardo Caballero Calderón, dibujos de Alberto Arango Uribe. Madrid: Guadarrama

\section{Introducción}

Con esta ponencia se pretenden ensanchar las distintas posibilidades que ofrece el estudio de la novela Asistencia y Camas (1934) y otras obras cortas de Rafael Arango Villegas (Manizales, 1899-1952). La pretensión es otorgarle a estas obras la connotación de herramientas para hacer historia, a partir de un análisis narrativo, que vincule y distinga lo diacrónico y lo sincrónico en la construcción de representaciones y de imaginarios puestos en conflicto. En la obra de este manizalita (además de características cómicas, literarias costumbristas y/o realistas) se percibe una relación dialéctica y material entre modernidad y tradición, propia de un momento histórico particular, que desde los discursos dominantes estaban en una etapa de reconfiguración discursiva pero de continuidad administrativa; a la vez que en los ámbitos sociales, culturales y económicos se percibía que el fuerte torrente que impulsaba los procesos de modernidad y modernización, se desaceleraba por el gran peso que ejercía en las personas la tradición, en cuanto a la manera como estas se relacionaban social y materialmente.

Es en esta relación dialéctica que encontramos el valor histórico de Asistencia y Camas y de Rafael Arango, que más que un retrato del papel de la 
mujer paisa, o el reflejo de la influencia de la picaresca española en la narrativa de Arango, ofrece la posibilidad de reconstruir a partir de la narrativa (con el soporte de otras fuentes) un escenario cultural/regional, que por estar expuesto a la convergencia de diferentes discursos es susceptible a la creación y a la transformación. La relación modernidad/tradición, que de una u otra forma recoge, tergiversa, de-construye y reconstruye todo un pasado común (colonial, decimonónico), afecta fáctica y cotidianamente la cultura (prácticas y representaciones) de los habitantes de la "región paisa" en la primera mitad del siglo XX, región y temporalidad que son el insumo para la obra de Rafael Arango Villegas.

\section{Función histórica de la novela Asistencia y Camas}

La pretensión de hacer Historia a partir de una obra literaria, acarrea varias cuestiones que se tienen que considerar y aclarar para poder tener una mejor comprensión de lo mencionado en esta propuesta. Una de las preguntas que pueden resultar frente a esta propuesta de investigación puede ser ¿por qué convertir la novela Asistencia y camas de Rafael Arango Villegas en un referente para hacer Historia? Para responder esta pregunta miraremos la relación que han tenido, dentro de la Historiografía nacional, la Literatura y la Historia, respectivamente.

El carácter ficcional atribuido a la Literatura, es una característica que ha servido para menospreciarla en relación con la Historia y la veracidad de lo escrito. La irrupción de la novela histórica como la posibilidad de una Historia alejada del dogmatismo y del documento, ha sido deslegitimada por las academias de Historia. De las licencias de los autores para recrear/inventar personajes y escenarios, la presencia de mundos idealizados, la ausencia de hechos y actores históricos reconocidos por un imaginario colectivo, se han tomado argumentos para distanciar la novela de la Historia. La historiografía anterior al giro lingüístico, en su afán de consolidar su estatus científico (medible y comprobable), miró con recelo la posibilidad de considerar la novela como referente histórico. La tradición de la novela histórica en Colombia que en las líneas de Temístocles Avella Mendoza, Lorenzo Marroquín, Rómulo Cuesta, Clímaco Soto Borda, Eustaquio Palacios, Pío Alberto Ferro o José Caicedo Rojas (Ayala, 2002: 34), ha recreado 
las guerras civiles decimonónicas, ha chocado de frente con la universalidad pretendida de la Historia académica que se vale de argumentos que van desde el principio de autor y el sesgo ideológico que acarrea, hasta la inexactitud en hechos, fechas y lugares.

No obstante, en las novelas (históricas o no) se puede ver recreado el llamado espíritu de la época. Sería un error y además una ingenuidad creer que el novelista reflejará con total exactitud acontecimientos históricos, por varias razones: la novela histórica utiliza fuentes las cuales son a la vez susceptibles a interpretaciones; la cultura, las vivencias y el insumo narrativo del escritor se traducirán en la construcción de una trama tropológica (White, 2003: 112) que manifiesta, más que la veracidad de los hechos, el mundo que quisiera el autor. Más que hechos históricos veraces, en la novela debemos buscar representaciones históricas e imaginarios en permanente conflicto.

Ya sea desde el realismo social o desde el realismo costumbrista, Asistencia y camas sin pertenecer al cánon de la novela histórica, es un texto apropiado para hacer Historia. Porque como agente de las representaciones del presente, la narrativa de Arango Villegas adquiere un alto poder de legitimidad al saberse presente; no sólo como hecho narrativo susceptible de historiar, sino como divulgador, reproductor o distorsionador de las tradiciones que nos llegan desde el pasado en cualquiera de estas tres formas, dando cuenta de la relación pasado-presente, insoslayable para los historiadores. Además de lo anterior, Asistencia y camas es apropiada para hacer Historia; pues entre las prácticas culturales propias de las gentes de una región, como los roles de la mujer caldense y la recreación de personajes reales (acompañados de sus vicios e imperfecciones), se encuentran mimetizadas representaciones históricas en conflicto e imaginarios que las distorsionan. Por demás, en esta novela publicada en 1934 se advierten características que nos entregan elementos para poder imaginar y construir el llamado espíritu de la época en un escenario específico. Los y las personajes (Julito, Silverio Antonio, Petra, Rosita y su hermana, Serna, El Sirio, Tránsito, la pareja de campesinos, entre otros) no están gratuitamente en la imaginación del autor y tampoco son extrapolaciones inertes de personajes de la Historia o la Literatura, éstos dan cuenta de las culturas y de las imbricaciones, rupturas, continuidades y discontinuidades entre éstas. 
Los personajes construidos por Arango Villegas son una pequeña parte de la radiografía social caldense y por tanto encarnan su cotidianidad, es decir, la forma de vivir de las gentes en el Caldas que entraba en el siglo XX. También los escenarios urbano/rurales recreados por Arango nos trasladan a la plaza de mercado, a los viajes a caballo por carreteras sin pavimentar, a la iglesia, a la estación de policía, a la barbería, a la cantina, a las ferias y carnavales, a las posadas $u$ hoteles y por supuesto a las asistencias. ¿Quién de los detractores de la novela como referente histórico va a negar la existencia de estos lugares y la importancia de estos como espacios de sociabilidad, de intercambio y construcción cultural? Los escenarios ofrecen objetos con los que se relacionan los personajes, contribuyendo a la construcción de un mapa urbano-históricosocial. Es precisamente aquí en donde encontramos a Arango Villegas como hombre-signo (Vallejo y Laverde, 2009: 64), producto de una enunciación, de un contexto histórico/local particular, de un espesor literario compuesto de estilos culturales y codificaciones literarias que se dirimen entre la actualidad y el desuso, del encuentro (mestizo) y desencuentro entre narrativas producidas en contextos culturales distanciados temporal y espacialmente, de una experiencia económica y política que desde el siglo XIX coincidía y fluctuaba entre conservadora y/o liberal, de una cultura que por más católica-cristiana que se pretendiera desde las instituciones nacionales, se manifestaba en su diversidad. Es en todo caso un escenario evidentemente polémico, el cual proporcionará los elementos necesarios para aportar hacia la construcción de una configuración discursiva, que pugnará (sin llegar a sobrepasarlas ni a desvirtuarlas por completo) con las otras categorías utilizadas para clasificar la narrativa de Rafael Arango Villegas.

Las formas de usar el lenguaje y de construir dialectos, además de su capacidad de aportar hacia la construcción de identidad, manifiestan una forma particular del mestizaje y por ende es objeto de la Historia Cultural. El uso de los fonemas de manera distorsionada o no-oficial, como por ejemplo cuando Arango Villegas en Asistencia y Camas, describe una conversación entre la señora Petra y su hijo Julito, en la cual ante una propuesta absurda del hijo doña Petra le responde: "¿usted está borracho, mijo, o es que se está empendejando?" (Arango Villegas, 1961: 98), no es un ultraje al idioma. Además de manifestarse ante la pretendida homogeneidad que pretende la literatura nacional, exaltando lo particular de su región e inscribiéndolo en una compleja realidad simbólica que le 
permite existir y ubicarse en el ámbito nacional, es la prueba de la capacidad creadora que tiene la cultura de reinventarse constantemente, que no se nota por el peso de la cotidianidad, pero que está presente en la posibilidad de las ideas y en la materialización de las mismas. Se podría decir entonces que frente a la imposibilidad de un método único de hacer Historia, además de la valoración de la novela como un instrumento loable para darle más realismo a la forma de escribirla, con ésta se abre un abanico de representaciones histórico-culturales que se traducirán en imágenes susceptibles de interpretación histórica.

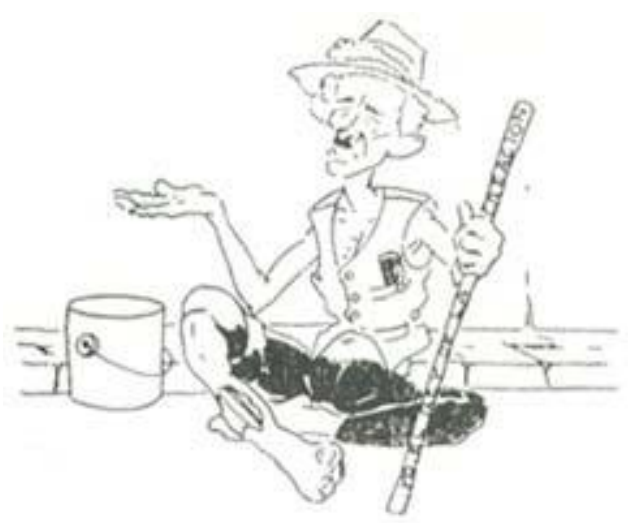

Fuente: llustración para el relato ¡Casi nada de epidemia! De la obra Bobadas mías de 1933. Editorial Arturo Zapata. Manizales

\section{Una contienda narrativa: tradición vs modernidad}

El camino hacia adelante que suponían nociones y reglamentaciones de la economía política, la modernidad, la industrialización, etc. parecía no tener objeción. La fe que se tenía en el progreso marcaba unos límites discursivos que empujaba a los gobiernos colombianos a insertarse en un proyecto de economía capitalista. No obstante esta misma idea llevó a que otros actores, caso de Rafael Arango Villegas, no confiaran del todo en el progreso y la modernidad, manifestándolo en su narrativa. Rafael Arango Villegas fue autor de varios libros que en su mayoría se componen de relatos cortos y una novela; escribió para periódicos de varias ciudades, además de desempeñarse durante algún tiempo como estadista del departamento de Caldas. Este caldense advertía que esta 
apuesta gubernamental hacia el capitalismo habría de aparejar rupturas y cambios de tipo cultural, además de económico. Pretendemos explicar cómo desde su narrativa, en la cual se encuentra la descripción de las prácticas y las normas morales que se han construido por la fuerza de la costumbre y la tradición, Rafael Arango Villegas plantea una contienda narrativa. Esta contienda narrativa se hace visible cuando destaca elementos de la cultura popular y los contrasta con los postulados modernos y con la materialización de la modernización (Londoño Rendón, 2002: 1-3).

No obstante, fueron las relaciones sociales de los diferentes tiempos y contextos urbano-geográficos las que dieron forma a la contienda narrativa planteada en la obra de Arango. Para 1934, fecha que se tiene como referencia de publicación de Asistencia y Camas, no eran muchas las ciudades modernas en Colombia. Se había configurado un escenario cuatricéfalo: las más altas cifras demográficas y de urbanización correspondían a Bogotá, Cali, Medellín y Barranquilla (Borja y Castells, 1998: 98). Por demás, en otras regiones de Colombia pervivían todavía muchas características de las viejas relaciones sociales propias del siglo XVIII. Muchos nombres habían cambiado y los trabajadores no llamaban "amo" a su patrón y los patronos no llamaban "esclavos" a sus trabajadores campesinos, pero al igual que en el siglo XVIII, los campesinos pertenecían a la tierra. Habían varias categorías de campesinos, siempre relacionados con su pertenecía o filiación con la tierra y con la familia. Eran elementos de la familia campesina: el predio familiar, el sistema de agricultura de subsistencia y la base técnica tradicional, el vecindario o vereda, costumbres y obligaciones morales, etc. Los campesinos se ubicaban en la escala más baja de la sociedad, caso de los colonos en posesión, los arrendatarios y los jornaleros o peones sin tierra, o las comunidades indígenas hispanizadas (Palacios, 2011: 5169). Las incoherencias resultantes de la pretensión de adaptar el país a un modelo económico capitalista pero sin transformar las relaciones sociales de producción (Kalmanovitz, 1985: 93-168), y la imposibilidad de consolidar un producto nacional, antes de que el precio internacional del café impulsara la propagación de fincas cafeteras, y aleatoriamente centros urbanos para comercializar y procurarse de los medios para proseguir con la faena cafetera, condujeron a que el campo colombiano permaneciera como congelado en el tiempo, con sus formas culturales 
coloniales, escuchando a lo lejos los azares de la política sin que esto cambiara fácticamente la cotidianidad de su vida.

La oportunidad histórica y económica de las élites colombianas de poder consolidar un producto nacional se presentó con la economía cafetera. Fue el café y todo lo que se requería para su producción y su comercialización el producto que jalonó la añorada industrialización y urbanización que estaban aguardando los grandes capitalistas del acero, del hierro y del asfalto. Entonces se hicieron necesarias vías de comunicación para que se pudiera sacar el café de las fincas y para llevar los insumos a éstas, además de la necesidad de gastar más energía y de la utilización de medios de transporte de tracción mecánica. La colonización cafetera impulsó el desarrollo urbanístico y con este la transformación del paisaje. Pero el cambio no podía ser solamente paisajístico, la mentalidad también estaba cambiando, el hombre moderno colombiano que parecía no poder despertar en el siglo XIX contaba ahora, bajo la batuta del café, con la posibilidad de salir de su anquilosada cotidianidad y alimentarse de lo que ofrecía el mundo, así como el café colombiano se abría paso en nuevos mercados. El anhelo de los gobiernos, sea cual fuere su tendencia, de modernizar al país por fin parecía tener viabilidad.

Estos tiempos, de esperanzas y nuevas ciudades cafeteras, de emergencia de ideas modernas y propuestas modernizadoras, eran los tiempos de Rafael Arango Villegas. Es precisamente en este escenario cuando todo apuntaba hacia adelante, cuando parecía que el progreso, la industrialización, la urbanización, la economía capitalista y la sociedad moderna traerían la esperada felicidad para el colombiano común, cuando Arango Villegas estaba escribiendo su prosa. En sus relatos, las prácticas y las normas morales están plasmados en sus personajes y en las relaciones entre éstos; ya sea en talante cómico, descontextualizando los lenguajes de las disciplinas, pareciendo inocente, Arango nos permite adentrarnos en la psicología del colombiano común que no iba a la universidad, que vivía entre las siembras y cosechas; las idas al pueblo en los días santos y lo que su dios dispusiera de su alma. En la simpleza de su prosa se mezclan la tradición y las costumbres propios de un contexto y un tiempo herederos del proceso colonial y el desconcertante, pero igual Godofredo, ${ }^{1}$ siglo XIX. En su contienda narrativa,

\footnotetext{
${ }^{1}$ Godofredo se refiere al término godo (conservador). No se pretende negar la influencia del liberalismo en el siglo XIX, sólo que haciendo un balance de la injerencia de las diferentes
} 
Arango enfrenta los postulados mencionados, sus aliados son la sabiduría de quienes habitaban la tierra, quienes habían recibido las enseñanzas de otros que las habitaron antes que ellos; y al igual estos un día fueron nietos e hijos de otros que en calidad de arrendatarios, aparceros, pequeños propietarios e incluso capataces habían recibido las reglas morales y la manera de hacer las cosas que los hacían parte de un grupo más grande de personas, una comunidad mayor (parroquia, poblado, vereda, gobernación, etc.), desde lo más mínimo como tomar el chocolate hasta el entierro y el velorio de sus muertos.

Llegados a este punto, emplearemos un pequeño relato de no más de cinco páginas para analizarlo desde la perspectiva de la contienda narrativa. Curiosa pero no inconscientemente, Arango toma un ejemplo simple, el de la siembra de café de forma científica y deja ver la trampa de creer que los métodos y técnicas modernas ${ }^{2}$ traen consigo más beneficio que la acostumbrada manera de hacer las cosas. En uno de sus relatos, Sal de la tierra, Arango propone una conversación en la cual uno de los participantes en su calidad de emisor le pregunta a otro " $¿ y$ por qué el cafeto ya no da granos?" a lo que su interlocutor contesta:

¡Pues porque no le dejamos donde! O usted cree que un árbol de café o de cualquiera otra clase, puede producir alguna fruta, si mantiene un peón al lado, con un machete en la mano, aventándole filo por todos cuatro costados ¡Así no produce ni el diablo! (Arango Villegas, 1961: 231).

Arango da a entender como la introducción de técnicas extrañas a las aprendidas por las prácticas locales y saberes consuetudinarios no logran los resultados que supuestamente se deberían obtener al implementar los métodos modernos de agricultura. Era todo lo contrario, el uso de técnicas extranjeras que pareciera (pero nunca lo logra) querer borrar de tajo el saber cultural y las prácticas consuetudinarias de siembra, privilegiando una homogeneidad en los

tendencias se advierte una herencia (apuntalada por la manera como termino la centuria) preferentemente conservadora.

${ }^{2}$ No hemos efectuado una exhaustiva investigación del grado de tecnificación industrial de las fincas cafeteras. Nos basamos únicamente en los relatos de Arango. 
sembrados y paisajes campesinos, pasma el fruto del árbol (según el relato de Arango). Las demandas del mundo moderno, llevaban aparejadas exigencias para los campesinos y para la misma tierra. ${ }^{3}$ Estas exigencias eran de índole productiva, que en su requerimiento de más cosecha enrarecían el ciclo natural y biológico de la tierra, forzándola hasta su extremo con la inevitable consecuencia de la esterilidad. Ese es el "peón que le avienta filo por los costados", aquel que en su afán de satisfacer las demandas del mundo moderno succiona y succiona sin devolver nada a la tierra.

La conversa sigue y ante la pregunta del porvenir de la industria cafetera, la respuesta es tajante:

Malísimo. Con el recargo de gastos innecesarios se ha hecho nugatoria. Y si siguen contemplando esos palos, y elegantizándolos, y gastándoles dinero inútilmente, van a eliminar el negocio (Arango Villegas, 1961: 232).

En esos cuatro renglones Arango reflexiona y hace acertados augurios a propósito del manejo geopolítico que se hace del mercado mundial de la agricultura. Le estrategia, legitimada por la noción de desarrollo que se vendió desde los países que se autoproclamaron como desarrollados, de endeudar a los agricultores locales con el fetiche de la tecnología y el rendimiento, construyó unas fincas agroindustriales dependientes de la ingeniería de los países llamados desarrollados. Tal ingeniería, la que consumen los agricultores locales, es obsoleta pero legitíma su entrada a las fincas de estos agricultores por tratados comerciales que crearon una dependencia de la agricultura local a la ingeniería internacional. A continuación Arango nos muestra el conocimiento inherente al saber de la tradición y la costumbre, en estas bellas líneas. El interlocutor inicial, del que no se tiene una referencia exacta, ante la pregunta de este de cuál es el mejor abono para el cafeto, le contesta al diputado de la "cuchilla atravesada":

El cafeto no necesita abono siempre que este sembrado en un terreno adecuado. Y cuando no lo esté, debe echársele el mismo abono que se 
les echa a las carrilleras: balasto. La prueba es que donde mejor pega esa maleza es en los cascajeros. El cafeto -repito- es una maleza cualquiera y produce mejor en estado silvestre. Los más bellos ejemplares los he visto siempre dentro del monte. En la huerta de una tía mía había, en tiempos anteriores, un árbol de café en el más completo abandono. Era el dormitorio de las gallinas y en el echaba las siestas un perro de monte que tenía mi tía (a estos palitos de ahora no se les puede asentar un "pinche" porque la cosecha se pierde). Tenía además el susodicho palo varios nidos de garrapatero, pero no nidos como los de ahora, que son tres chamizas trabadas. Lo cierto es que nosotros le cogíamos café para tirar en la cuca, mi tía le cogía para el consumo en la casa, y el resto lo exportaba don Luis Jaramillo Walker (Arango Villegas, 1961: 233).

Este último aparte lleno de una sencillez y una sabiduría que asombran, es la bandera que pone el vencedor en la parte más alta del castillo de los vencidos. No obstante todos los argumentos que se pueden esgrimir desde las teorías de la economía política, o desde la liberalización de los mercados, desde la necesidad de individualizar la tierra se encuentran con una sabiduría ancestral que desde sus prácticas y sus tradiciones halla el verdadero sentido que la une a su terruño, a los suyos.

\section{Consideraciones Finales}

Todo lo anterior constituye apenas un ejemplo de la gran posibilidad que nos ofrece Arango Villegas. Tenemos que decir que no fue Arango un político defensor de la causa obrera, ni militante del partido comunista, fue una persona que vivió en la primera mitad del pasado siglo y que advirtió que mimetizado en las ideas de la modernidad y de la modernización podía sustituir sus tradiciones por un lenguaje más técnico y sus costumbres por una tendencia homogenizante. Para terminar aclaramos que no hemos hecho un estudio del comportamiento de las cosechas del café. Este análisis se apoyó única exclusivamente en el relato de Arango Villegas: reportaje futurista, interpretación histórico-literaria de un autor que lleva más de sesenta años de fallecido. No obstante, el ejercicio da cuenta de un diálogo pasado-presente (Selden, 1989: 138); desde las preguntas que nuestra cotidianidad le hace a la prosa de Arango Villegas se manifiestan inquietudes y lagunas que se intentan rellenar, situaciones históricas que se pretenden 
replantear y abrir el espectro de las posibilidades, desvirtuar la unidireccional historia patria, elitista, económico- institucional y darle oportunidad a quienes desde una plaza, parcela o pequeña casa se acomodaban al peso de las estructuras y les daban forma en sus propios contextos.

Pero esta deconstrucción que se hace de la modernidad no es un capricho, es producto de las inquietudes que generan las actuales condiciones históricas. Nace de la desazón, del vacío de no poder comprender el espíritu de los tiempos, de la impotencia que se siente cuando no se puede detener la transformacióndestrucción del entorno que es vida por sí mismo, que remplaza la belleza de un río cristalino por la turbiedad que dejan las grandes retroexcavadoras en su afán de perforar la tierra en búsqueda de minerales, combustibles fósiles, o cualquier otra sustancia requerida para alimentar el mercado; nace del desaliento que dejan miles y miles de hectáreas taladas, de la destrucción de los ecosistemas a los que se les cambia el nombre, enunciándolos como recursos para así poder naturalizar y justificar la intervención, el saqueo y la inevitable destrucción de formas de vida mucho más antiguas que la misma humanidad. Esta deconstrucción que se hace de la modernidad es una reacción instintiva a la imposición de un discurso extraño, excluyente y opresivo; que se esconde tras la máscara de la añorada felicidad del individuo liberal, mientras socava, destruye y transforma los imaginarios capaces de cimentar formas de vivir más armónicas con nosotros mismos, nuestro entorno y nuestra comunidad. ¿No se nos hace de suma extrañeza la celeridad que imprimimos a nuestros actos cotidianos? ¿No sufrimos cuando no entendemos por qué el tiempo del día no alcanza para lo que teníamos presupuestado alcanzara? ¿No maldecimos cuando la necesidad de cumplir nuestros roles sociales nos conduce a un sistema masivo de transporte público al cual llaman "moderno"? Las reglas de juego impuestas desde el ideal de la modernidad pretenden tergiversar costumbres y tradiciones que hacían nudo al interior de las comunidades, para imponer una visión individual-capitalista que no se detiene ni siente respeto por lo que sí es vida. El discurso moderno venido de afuera impone un solo modelo de modernidad negando la posibilidad a otras modernidades.

Los tiempos actuales nos abruman por el desfase que percibimos, nos deprimen porque el sentido de la vida queda reducido a los roles sociales y familiares construidos razonablemente desde la homogenización, ipero también 
nos despierta! El tiempo y el lugar que nos enmarca y que proyecta nuestra conciencia se nos hace tan extraño, que si bien se puede convertir en un mundo sin esperanza, nos golpea existencialmente de tal forma que nos invita a reaccionar y a construir posibilidades histórico-narrativas que llamen la atención de esta situación y se manifieste en la medida que cuente historias que trasgredan y pongan en cuestión el discurso impositivo, excluyente y homogenizante. Hay una necesidad de comprensión de sí mismo visible en la forma como se lee a Arango Villegas, es un despertar, es un cuestionamiento al porque nuestro trabajo no nos dignifica pero sí engorda los bolsillos de capitalistas, corporaciones y corredores de bolsa; es preguntarse porque se hace tan indispensable la confrontación bélica como estrategia geopolítica y el establecimiento de la democracia en todas partes como evidencia del avance de las naciones, es la no comprensión de porque no ha llegado a la mayoría la felicidad prometida para el hombre moderno-occidental, sino al que por el contrario le han reducido su sentido de vida, limitándolo cultural y artísticamente.

\section{Referencias Bibliográficas Fuentes Bibliográficas.}

ARANGO Villegas, Rafael (1961). Obras Completas. Medellín: Togilber.

AYALA, Fernando (2002). Manual de Literatura Colombiana. Bogotá: Panamericana.

BORJA, Jordi y Castells, Manuel Castells (1998). La gestión de las ciudades en la era de la información. Chile: Pontificia Universidad Católica de Chile.

KALMANOVITZ, Salomón (1985). Economía y Nación. Una Breve Historia De Colombia. Bogotá: Bedout.

LONDOÑO Rendón, Carlos (2002). "Procesos de modernización sin modernidad en América Latina (Esquema de ideas)". Medellín: Universidad Pontificia Bolivariana. Consultado 15 abril de 2014. cmap.upb.edu.co/.../EsquemaProcesosModernizacionAmericaLatina.doc

PALACIOS, Marco (2011). ¿De Quién es la Tierra? Propiedad, politización y protesta campesina en la década de 1930. Bogotá: Fondo de Cultura Económica.

SELDEN, Raman (1989). La Teoría Literaria Contemporánea. Barcelona: Ariel. 
VALLEJO, Olga y Laverde, Alfredo (coords) (2009). Visión Histórica de la Literatura Colombiana. Medellín: La Carreta Histórica.

WHITE, Hayden (2003). El Texto Histórico como Artefacto Literario y otros escritos. Barcelona: Paidós Ibérica. 